\title{
Bilateral asymmetrical multiple renal arteries associated with the left testicular artery
}

\author{
Y.J. Jeon ${ }^{1}$, J.N. Lee ${ }^{1}$, S.P. Yoon ${ }^{2}$ \\ ${ }^{1}$ Medical Course, School of Medicine, Jeju National University, Jeju-Do, Republic of Korea \\ ${ }^{2}$ Department of Anatomy, School of Medicine, Jeju National University, Jeju-Do, Republic of Korea
}

[Received 28 March 2014; Accepted 6 May 2014]

\begin{abstract}
We found 3 right and 2 left renal arteries with asymmetrical origins in a 61-year-old Korean male cadaver, whose cause of death was 'laryngeal carcinoma'. According to a previous classification, the first and second right renal arteries correspond to the early division and other renal arteries - to the extra renal arteries, except the first left renal artery as a typical renal artery. The third right renal artery ran anterior to the inferior vena cava to the inferior pole of the kidney. The first and second left renal arteries were associated with the inferior suprarenal artery and the testicular artery, respectively. The bilateral asymmetry in the number of renal arteries can be explained by the embryological development, degeneration and persistence of the renal artery in the process of ascending of kidneys (Folia Morphol 2014; 73, 4: 510-513).
\end{abstract}

Key words: embryology, renal artery, rete arteriosum urogenitale, variation

\section{INTRODUCTION}

Renal arteries typically branch from the lateral aspect of the abdominal aorta at the level of the upper margin of the second lumbar vertebral body. Variations of the renal vasculature are frequent, and the most common and clinically important is variation in the number of renal arteries [13]. These usually arise from the aorta or iliac arteries anywhere at the level of the $11^{\text {th }}$ thoracic vertebrae to the $4^{\text {th }}$ lumbar vertebrae or rarely from the lumbar, suprarenal, superior mesenteric, inferior mesenteric, middle sacral or inferior phrenic arteries. Additional renal arteries can be classified into two groups: the early division and the extra renal arteries [11]. The early division consists of the branching of the main renal arteries into segmental branches, which lay more proximal in terms of their origins. Extra renal arteries are subdivided into two groups: the hilar (accessory) and the polar (aberrant) arteries. The hilar arteries enter the kidneys from the hilus with the main renal artery, whereas the polar arteries enter the kidneys directly from the capsule outside the hilus.

Recently a great diversity of variations in renal arteries have been reported including bilateral quadruple renal arteries [8], bilateral triple renal arteries [14], bilateral multiple renal arteries associated with both testicular arteries [9], 9 renal arteries [4] and precaval renal artery [2]. In this report, we found an asymmetry of bilateral multiple renal arteries unlike former renal artery variations, since bilateral symmetry in the number of renal arteries was evident in $88.4 \%$ of cases [7].

\section{CASE REPORT}

During a routine dissection at Jeju National University Medical School in 2013, bilateral asymmetrical multiple renal arteries were observed in a 61-year-old

Address for correspondence: Dr S.P. Yoon, Department of Anatomy, School of Medicine, Jeju National University, 102 Jejudaehak-ro, Jeju-Si, Jeju-Do 690-756, Republic of Korea, tel: +82 64 7543823, fax: +82 64 7252593, e-mail: spyoon@jejunu.ac.kr 

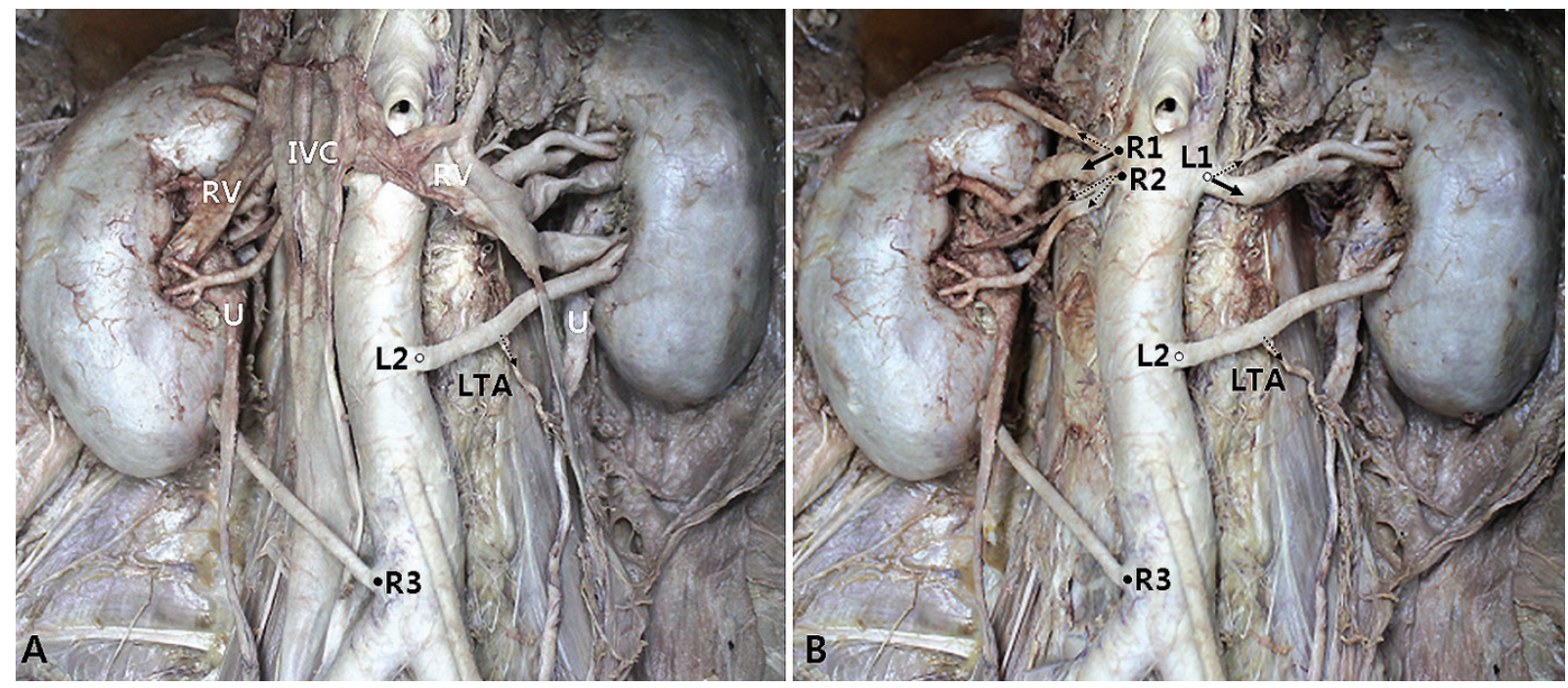

Figure 1. Before (A) and after (B) reflecting the inferior vena cava (IVC) and the renal veins (RV). The renal arteries are designated on the right side R1 to R3 (from most superior to most inferior), and similarly L1 to L2 on the left side. The main renal arteries are marked by arrows and branches are marked by dotted arrows. Note the precaval course of the R3; LTA — left testicular artery; U — ureter.

Table 1. Morphological parameters of the renal arteries. Additional renal arteries were grouped into the early division (ED) and the extra renal artery by a previous classification [11] and characteristics of each renal artery were summarised as follows. For ease of description and location, the authors designated the renal arteries on the right side R1 to R3 (from most superior to most inferior), and similarly L1 to L2 on the left side (also marked in Fig. 1)

\begin{tabular}{|c|c|c|c|c|c|}
\hline Variables & R1 & R2 & R3 & L1 & L2 \\
\hline Classification & $\begin{array}{l}\text { Main: hilar } \\
\text { ED (8 mm from } \\
\text { the origin): polar }\end{array}$ & $\begin{array}{l}\text { Main: hilar } \\
\text { ED ( } 3 \mathrm{~mm} \text { from } \\
\text { the origin): hilar }\end{array}$ & $\begin{array}{c}\text { Extra renal artery: } \\
\text { polar }\end{array}$ & Main: hilar & $\begin{array}{l}\text { Extra renal } \\
\text { artery: hilar }\end{array}$ \\
\hline External diameter at origin [mm] & $\begin{array}{l}\text { Main: } 6.5 \\
\text { ED: } 1.6\end{array}$ & $\begin{array}{l}\text { Main: } 3 \\
\text { ED: } 1.3\end{array}$ & 3.5 & 7 & 5 \\
\hline $\begin{array}{l}\text { Distance from the bifurcation of the } \\
\text { abdominal aorta [mm] }\end{array}$ & 118 & 110 & 30 & 111 & 69 \\
\hline Vertebrae level at origin & LV2 & LV2 & LV4 & LV2 & LV3 \\
\hline Renal segment supplied & $\begin{array}{l}\text { Anterior superior; } \\
\text { Apical; Posterior }\end{array}$ & Anterior inferior & Inferior & $\begin{array}{c}\text { Apical; Anterior } \\
\text { superior; Posterior }\end{array}$ & $\begin{array}{l}\text { Anterior inferior; } \\
\text { Inferior }\end{array}$ \\
\hline Other association & & & $\begin{array}{c}\text { Precaval renal } \\
\text { artery }\end{array}$ & $\begin{array}{l}\text { Inferior suprarenal } \\
\text { artery }\end{array}$ & $\begin{array}{l}\text { Left testicular } \\
\text { artery (1.5 mm } \\
\text { diameter) }\end{array}$ \\
\hline
\end{tabular}

LV2 — the second lumbar vertebrae; LV3 — the third lumbar vertebrae; LV4 — the fourth lumbar vertebrae

Korean male cadaver, whose cause of death was 'laryngeal carcinoma'. The protocol for the current report did not include any specific issue that needed to be approved by the ethics committee of our institution and it conformed to the provisions of the Declaration of Helsinki in 1995.

On the right side, the main renal artery arose from the abdominal aorta with early division (R1); the first additional renal artery - just below the main artery with early division (R2); the second artery with precaval course branches - from the anterolateral aspect of the abdominal aorta (R3). On the left side, the main renal artery (L1) and the additional renal artery (L2) arose from the lateral aspect of the abdominal aorta (Fig. 1).

For each renal artery, the authors analysed the external diameter at origin, distance from the bifurcation of the abdominal aorta, vertebrae level at origin, renal segment supplied and other characteristics (Table 1). For ease of description and location, the authors designated the renal arteries 
on the right side R1 to R3 (from most superior to most inferior) and similarly L1 to L2 on the left side. On each side, the first renal artery (the superior one) was the main renal artery and the additional arteries were located below the main renal artery. The main renal artery had the external diameter larger than the diameter of the additional renal artery at the origin.

\section{DISCUSSION}

Additional renal arteries are not a rare renal vascular variation. In a cadaveric study [12], 23\% had double renal arteries, $4 \%$ had triple arteries, and $1 \%$ had quadruple arteries. Bilateral variations occur in $6.3 \%, 0.2 \%$, and $0.1 \%$ for bilateral double, triple, and quadruple renal arteries, respectively [7]. In case of combined variations [1], $19.9 \%$ had double renal arteries, $11 \%$ had bilateral double arteries, $1.1 \%$ had double and triple renal arteries on the each side, and $1.1 \%$ had another urovascular variation, origin of the genital artery from the renal artery. Herein we report a rare case of an asymmetry of bilateral multiple renal arteries in a Korean male cadaver: 3 right and 2 left renal arteries with different origins at the abdominal aorta, and left testicular artery arising from the second left renal artery.

The additional arteries represent the vestiges of the embryological blood supply to the kidneys. A delay in the migration of the kidney into the lumbar region, or the persistence of the embryological structures, leads to anatomic variations [6]. The metanephros first lies in the pelvic cavity with the hilum being directed anteriorly, then ascends with the medial rotation of the hilum and it reaches the lumbar region with its hilus being directed antero-medially, and finally reaches the lumbar position with the hilum being rotated medially. As the kidneys ascend, the caudal branches disappear and the cranial ones persist. According to the observation by Felix [3], there are 9 pairs of arteries which supply the mesonephros, metanephros, gonads and the adrenal glands. These 9 pairs have been divided into the cranial (the $1^{\text {st }}$ and the $2^{\text {nd }}$ pair), middle (the $3^{\text {rd }}$ to the $5^{\text {th }}$ pair) and the caudal (the $6^{\text {th }}$ to the $9^{\text {th }}$ pair) groups. These mesonephric arteries form a vascular network from the lateral aorta, the so-called rete arteriosum urogenitale. This rich network involution leads to one symmetric mesonephric artery, the main renal artery on each side.

Therefore, more than one artery persists explaining the presence of additional renal arteries. In the right side of the present case, the remaining arteries of the cranial, middle, and caudal groups give rise to R1 with early division, R2 with early division, and R3 with precaval course, respectively. In the left side, persistence of middle and caudal groups correspond to $L 1$ with inferior suprarenal artery and L2 with left testicular artery, respectively. Gonadal artery originating from main renal artery or from its branches or from an accessory renal artery (about 15\%) is the most common gonadal vascular variation [10]. This can be explained by the fact that not only renal but also gonadal arteries arise from the abdominal lattice-like arterial structure [3]. Therefore, the persistence of multiple renal arteries might increase the incidence of gonadal arteries arising from renal arteries, like in this case.

Knowledge of the potential anatomic variations is significant for clinicians. The complex variations, like in this case, are important as to renovascular hypertension, renal and testicular infarction during urologic or oncologic surgical intervention and renal transplantation [5, 9]. The lower polar arteries, such as R3 with precaval course in this case, often result in ureteral complications and deserve special attention as its damage can induce necrosis of the ureter or hydronephrosis [2].

\section{CONCLUSIONS}

Taken together, we found a rare case of an asymmetry of bilateral multiple renal arteries with different origins in a Korean male cadaver. Associated variations including early division and the left testicular artery can be explained by the embryological development and degeneration of the renal artery in the process of ascending of kidneys. It is important to be aware of the anatomy and potential congenital anomalies of the renal arteries.

\section{REFERENCES}

1. Bordei P, Sapte E, Iliescu D (2004) Double renal arteries originating from the aorta. Surg Radiol Anat, 26: 474-479 .

2. Bouali $\mathrm{O}$, Labarre $\mathrm{D}$, Molinier $\mathrm{F}$, Lopez $\mathrm{R}$, Benouaich $\mathrm{V}$, Lauwers F, Moscovici J (2012) Anatomic variations of the renal vessels: focus on the precaval right renal artery. Surg Radiol Anat, 34: 441-446.

3. Felix W (1912) The development of the urogenital organs. In: Keibel F, Mall FP eds. Manual of human embryology. J.B. Lippincott Company, Philadelphia, pp. 752-880.

4. Hirai S, Honma S, Naito M, Terayama H, Kawata S, Itoh M (2013) Nine renal arteries in a Japanese female cadaver. Anat Sci Int, 88: 118-121. 
5. Khamanarong K, Prachaney P, Utraravichien A, Tong-Un T, Sripaoraya K (2004) Anatomy of renal arterial supply. Clin Anat, 17: 334-336.

6. Krishnaveni C, Kulkarni R (2013) A right ectopic kidney with bilateral multiple anomalies of the renal vasculature: a case report. J Clin Diagn Res, 7: 150-153.

7. Matusz P, Miclaus GD, Ples H (2011) Study of the renal additional arteries on the 1,000 CT angiography continuous series. (Abstract presented at the Australian and New Zealand Association of Clinical Anatomists $7^{\text {th }}$ Annual Meeting). Clin Anat, 24: 408.

8. Miclaus GD, Matusz P (2012) Bilateral quadruple renal arteries. Clin Anat, 25: 973-976.

9. Naito M, Hirai S, Terayama H, Qu N, Yi SQ, Miyaki T, Itoh M (2011) Multiple renal vessels associated with testicular vessels. Surg Radiol Anat, 33: 637-639.
10. Notokovich H (1956) Variations of the testicular and ovarian arteries in relation to the renal pedicle. Surg Gynecol Obstet, 103: 487-495.

11. Ozkan U, Oğuzkurt L, Tercan F, Kizilkiliç O, Koç Z, Koca N (2006) Renal artery origins and variations: angiographic evaluation of 855 consecutive patients. Diagn Interv Radiol, 12: 183-186.

12. Pollak R, Prusak BF, Mozes MF (1986) Anatomic abnormalities of cadaver kidneys procured for purposes of transplantation. Am Surg, 52: 233-235.

13. Shakeri $A B$, Tubbs RS, Shoja MM, Pezeshk P, Farahani RM, Khaki AA, Ezzati F, Seyednejad F (2007) Bipolar supernumerary renal artery. Surg Radiol Anat, 29: 89-92.

14. Uzmansel D, Ozturk NC, Kara A, Ozturk H (2014) A rare combination of vascular variations of both kidneys. Surg Radiol Anat, 36: 195-198. 